\title{
ОЦЕНКА ПРЕПОДАВАНИЯ И ОБУЧЕНИЯ
}

\section{ОБ3ОР СТАТЬИ}

PINTO, Jacyguara Costa ${ }^{1}$

RODRIGUES, Helton Barbosa ${ }^{2}$

SILVA, Vanessa de Souza da ${ }^{3}$

PINTO, Jacyguara Costa. RODRIGUES, Helton Barbosa. SILVA, Vanessa de Souza da. Оценка преподавания и обучения. Revista Científica Multidisciplinar Núcleo do Conhecimento. 04 год, Эд. 11, Vol. 03, стр. 81-90. Ноябрь 2019 года. ISSN: 24480959, ссылка для

доступа: https://www.nucleodoconhecimento.com.br/oбразование-ru/оценкапреподавания

\section{PEЗЮME}

В статье представлены исследования о новых вызовах, связанных с образованием, и важно подумать о модели оценки, используемой учителями сегодня. Поэтому мы стремились проанализировать процессы планирования

\footnotetext{
${ }^{1}$ Doutor em Ciência da Educação, Mestre em Ciência da Educação, Especialista Lato Sensu em Docência de Ensino Superior, Especialista Lato Sensu Em História cultura, Literatura Africana, afro-brasileira, licenciado e Bacharel em História.

2 Mestre em Ciência da Educação, Licenciatura Plena e Bacharel em Geografia, Especialista Lato Sensu em Gestão Ambiental, professor da Rede pública estadual, atualmente exercendo suas funções de docente na educação básica no Sistema Organizacional ensino Modular do Estado do Amapá.

${ }^{3}$ Mestrando em Ciência da Educação, Especialista em ensino especial, Licenciada plena pedagogia, professora da rede pública Estadual e Municipal no Estado do Amapá.
} 
оценки, проведенные в начальных классах начальной школы. Результаты были получены с помощью библиографического метода исследования описательного характера и качественного подхода, проведения анализа содержания книг и научных статей, что позволило соединить исследования и эмпирические перспективы исследователя, направляя построение результатов в трех разделах, которые были описаны с этого момента. При разработке статьи была проанализирована оценка преподавания и обучения, а также была описана важность самооценки беспристрастного педагога; и, можно вкратце понять, принятие оценки участия по целям в образовательной реальности начальной школы. Был сделан вывод о том, что на проблему статьи был дан ответ, была достигнута общая цель и подтверждена гипотеза о том, что любой инструмент, используемый учителями и школой для проведения оценки, настраивает способ установления уровня обучения, признания наилучших и худших, и особенно, адаптации преподавания к стандартам передового опыта, установленным школой. Стандартизированные меры отвлекли демократическое, критическое, конструктивное и творческое чувство оценки, препятствуя эфффективному обучению.

Ключевые слова: Оценка, компетенции, производительность, цели, школа.

\section{1. ВВЕДЕНИЕ}

Образование в нашей стране достаточно сложное, сегрегация общества разрушила группы людей, которые являются жертвами неравенства, которые являются отражением инкурии государственной власти.

Эти различия отражают отношения, которые существуют в школе. Заставить человека усомниться в их условиях, как существо, способное строить свои представления о человеке, обществе и мире, в поисках удовлетворения своих потребностей в различных измерениях и в то же время узаконить свою самобытность перед своими сверстниками. 
Учитывая новые проблемы, поставленные перед образованием, важно подумать о модели оценки, используемой учителями сегодня, учитывая, что акт оценки, независимо от того, что модель принята, не является нейтральным, поскольку она приносит в своем выпуклости определенный способ зачатия реальности, личности и общества, направляя и кондиционируя педагогическую практику, существующую в классе и в школе.

Независимо от инструмента, используемого учителями и школой для выполнения оценки, он настраивает определенные, установить уровень обучения, признать лучшие и худшие, и особенно адаптировать преподавание к стандартам передового опыта, установленных в школе. Стандартизированные меры отвлекли демократическое, критическое, конструктивное и творческое чувство оценки, препятствуя эффрективному обучению. Основываясь на этих предположениях, расследование начинается со следующей проблемы: Какая связь существует между планированием действий школьной оценки с улучшением успеваемости ученика?

Таким образом, оправдано размышлять о процессах, связанных с планированием оценки школы как момент обучения, средством, в котором учитель использует для посредничества знаний, а не конец, так как оценка не ограничивается только определение классов, но следует по пути, что студент идет, обнаруживает свои трудности и изменения направления при необходимости.

Таким образом, целью статьи было проанализировать процессы планирования оценки, проводимые в начальных классах начальной школы. В частности, она предназначена для анализа оценки преподавания и обучения; описать важность самооценки беспристрастного педагога; и, чтобы понять принятие участия оценки целей в образовательной реальности начальной школы.

Результаты были получены с помощью библиографического метода исследования описательного характера и качественного подхода, проведения 
анализа содержания книг и научных статей, что позволило соединить исследования и эмпирические перспективы исследователя, направляя построение результатов в трех разделах, которые были описаны с этого момента.

\section{2. ОБ ОБУЧЕНИИ И ОЦЕНКЕ ОБУЧЕНИЯ}

В соответствии со временем и моделью общества, оценка имеет свою траекторию с самых ранних времен. Некоторые авторы, такие, как Soeiro и Aveline (1982) выявили в качестве источника методов оценки деятельность, которую первые человеческие конгломераты выполняли, с помощью ритуалов, делают молодых коренных народов готовыми быть коренными взрослыми. Для этих авторов, такая практика восходит к 360.Вс рассматривается как система критериев, используемых китайцами и греками, чтобы позволить людям для данной работы, что позволяет всем гражданам достичь должности престижа и власти.

C самого начала уже были способы оценки, акт, используемый китайцами и греками на рынке труда, это произошло бессознательно, навязанные культурной модели общества, с целью подготовки и выбора лучших для поддержания позиций престижа и власти. Эта модель оценки также использовалась в Китае в 2200 г. до н.э. (SOEIRO; AVELINE, 1982).

В Греции Сократ предложил самооценку, "знать себя", как способ добраться до истины. Таким образом, эта фрилософрская мысль стала формой экзамена, то есть самооценки, действием крайне важного в настоящее время для эффрективности учебно-учебного процесса.

Чтобы уделять больше внимания траектории оценки Despresbiteris (1999, стр. 113) сообщает, что в " 2005[...] г. до н.э. Китайский император Шум осматривал своих офрицеров каждые три года с целью поощрения или стрельбы, в первую очередь для обеспечения безопасности людей, обученных в обороне государства ". Другим важным примером того, как была разработана оценка, 
является работа Маркса, что "эксп[...]ертиза является не чем иным, как бюрократическим крещением священных знаний" (apud GARCIA, 2001, стр. 29).

Таким образом, экспертиза подчеркивается как бюрократия, то есть письменная часть, в которой сообщается только то, что подходит аппликаторам, в данном случае оно направлено на документацию, а не интеллектуальное развитие, используя то, что обыденно для изменений и преобразований в священное знание.

Также в xith столетии, Kraemer (2005) подвергает действию пользу экзамена как форма оценки через организованную дисциплину экзаменов и систему присваивать ранги, давая начало к науке вызванной Docimologia. B нем также поясняется, что в этимологическом смысле оценка исходит из латинского а а valere, имеющего как означающее значение и заслуги к цели исследования. Концепция, используемая в ряде стран, уже упомянутых направлена на отбор людей для выполнения различных функций на рынке труда.

С преобразованиями от технологической эры и индустриализации, от двадцатого столетия, исследование и оценка вытерпели большое влияние от наук, многочисленнNр процедуры и теории используемые сегодня были созданы, such as обзор и другие aп ${ }^{[4]}$ паратуры: стандартизированные цели и письменные испытания.

Вианна (2005) отмечает, что первые тридцать лет американской социальной жизни в двадцатом веке были под влиянием трех элементов, разработанных в принципе для промышленного управления: систематизация, стандартизация и эфффективность, которые в конечном итоге повлияли на все общество, в том числе в образовательной сфере. Таким образом, существует большая озабоченность по поводу рынка труда, эффрективность была великой целью и, следовательно, разрабатывает методы, чтобы определить, где студенты не смогли понять знания, преподаваемые в классе. 
В 1970-х годах, оценка в конечном итоге создание позитивистской парадигмы, которая должна быть нарушена со строительством новых форм оценки, применяя новинки, которые были в моде на североамериканском континенте. Так, были разработаны процедуры сравнения успеваемости учащихся с тестами и составом новых образовательных планов, включая оценку как процесс измерения этого показателя в дисциплинах. Для Прадо де Соуза (1998) именно с 1980-х годов оценка образования стала более актуальной в школьном контексте. Именно тогда социология начала вносить соответствующие исследования и исследования о внутренней работе школы.

Понятие обучения как объекта оценки является еще одним столпом в защите концепции образовательной оценки. Человеческое обучение не ограничивается приобретением знаний, навыков, норм поведения, «асептика» ценностей и личного смысла. Использование концепции обучения для описания когнитивных процессов и приобретений, за исключением "аффрективных" и "контивных", является непоследовательным, поскольку оно искажает реальность, которая предназначена аффективной и оценочной неизвестного измерения знаний. Все когнитивные действия имеют ценность, знания, навыки, форму поведения несет в себе личное чувство, это предмет, который учится. Оценка требует наличия объектной модели с цельной, целостной и многогранной точки зрения, которая подчеркивает сложность и богатство обучения. Они утверждают, что необходимость оценки преподавания или профессиональной подготовки (GIBBS, 2003).

\section{3. ВАЖНОСТЬ САМООЦЕНКИ БЕСПРИСТРАСТНОГО ПЕДАГОГА}

Самооценка была сочтена весьма эффрективной стратегией принятия демократических концепций в процессе управления школой, в результате чего граждане, руководители, учителя и все участники школьного сообщества стали участниками процесса выделения ресурсов в школьное образование (CAMILLONI, 1997). 
Схема самооценки состоит из того, чтобы внутренние и внешние процессы, в которых участвует школа, могли рационально измерять свои результаты и продемонстрировать эфффективность того, как эрофреогика и дидактика анализируют свое педагогическое и дидактическое планирование в стратегиях преподавания в классе, таким образом, есть самооценка, когда можно определить сильные стороны (потенции) и хрупкие (эфемерные) результаты.

Проблемы субъектов оценки заключается в том, чтобы подойти к обсуждению вопроса о том, кто должен, может и может участвовать в оценке. Он борется и защищает необходимость и право студента университета участвовать в его оценке, образовательной и учебной ценности, которая несет себя и другие предметы учебно-учебного процесса. Я и гетеро являются необходимыми аспектами индивидуальной и групповой работы в высшем образовании, которые укрепляют и выражают связь между работой группы и индивидуальной ответственностью каждого особого данью ей; внести свой вклад в развитие последипломной социальной ответственности как требования к высшему образованию. Она устанавливается в качестве законной цели, которая меняет оцениваемый оценщик.

Самооценка происходит через процессы, которые, когда учитель выполняет и принимает их, не хватает знаний относительно информации и критериев, которые должны быть оценены, поскольку они были выполнены теми, кто оценивает их, измерения их собственных результатов и учитывая, такие собственные результаты были удовлетворительными для успеха учебного процесса обучения. В этом случае учителя применяют тесты самооценки всякий раз, когда в классе и в других школьных помещениях преподаются курсы, лекции, тренинги и консультации.

Образовательная оценка, с момента своего происхождения, уже приносит в своей выпуклости сложности, в связи с многочисленными факторами, которые должны быть рассмотрены при оценке кого-то или что-то, и важно подчеркнуть, 
что в настоящее время осведомленность бразильского общества об актуальности процесса оценки образования.

Поэтому оценка необходима, и в большей степени, когда оценка рассматривается как официальное обязательство и неофициальная практика. Поскольку в настоящее время оценка понимается как незаменимое действие в любой момент в жизни человека, противопоставляя естественно на службе образования, приближается опыт обучения, человеческого развития, улучшение качества жизни, доброжелательность, повышение самооценки и доблести инициатив среди людей.

Обеспечение образования для всех связано с переходом от учебной программы, далекой от проблем мира и интересов самих студентов, к учебной программе, способной заинтересовать как студентов, так и учителей, благоприятствуя пониманию природных, социальных и культурных явлений, как инструмента, предрасположенного к допросу, обучению В действии, отношению к неопределенности сложности, учитывая новые знания, навыки и ценности.

Педагог должен пересмотреть свою праксис и дидактику, стремясь разработать более значительное содержание и более участие методологии, таким образом, что это уменьшает необходимость использования записки в качестве инструмента coertion. Эта задача непростая в современном контексте, эта работа педагога связана с борьбой с отчуждением: это борьба перспектив, смыслов для знания и для жизни.

В этом контексте ЛДБ как юридическое руководство по политике в области образования стремится восстановить через государственную школу свою роль в формировании гражданства, будучи открытым для всех учащихся, без дискриминации, интегрируя социально-культурное разнообразие и индивидуальные различия, тем самым способствуя интеграционной социализации. Образование в области гражданства указывает на способ решать новые проблемы, позволяя при этом интеграцию ценностей и перекрестных тем, 
вместо того, чтобы представлять их в качестве конкретных или изолированных действий, не ограничивая себя изучением определенных ценностей, поведения или взглядов, так как гражданин нуждается в целом наборе знаний и навыков, которые позволяют ему активно участвовать в общественной жизни , без которых вы можете быть исключены или лишены гражданства.

Однако по-прежнему существует много проблем, с которыми необходимо столкнуться, чтобы государственное образование было условием социальной сплоченности и интеграции: повышение эфффективности управления и увеличение плотности содержания; диалог между научными знаниями, системами интерпретации мира и исконной мудростью народов Латинской Америки; открыть школы для общества и их потребностей; определение базовых и базовых навыков для подготовки студентов с созданием информационнооценочных систем; большее социальное признание магистратуры, достойных и профрессиональных педагогов.

\section{4. ИСПОЛЬЗОВАНИЕ ОЦЕНКИ УЧАСТИЯ В ЦЕЛЯХ БРАЗИЛЬСКОГО БАЗОВОГО ОБРАЗОВАНИЯ}

В текущем контексте, оценка у нас до сих пор иногда путают с понятиями и оценками, и осуществляется для классификации студентов в утвержденных и неодобренных. Есть меньшинства, которые могут визуализировать и провести оценку, с тем чтобы внести свой вклад в квалификацию образовательного процесса. Большинство предпочитают сортировать оценки, потому что они думают, что это самый простой способ, чтобы они имели меньше работы.

Многие школы оценивают своих студентов с помощью экзаменов, практики, которые являются позитивистской и технической по своему характеру, которые не рассматривают обучение в целом, действуя в классификаторном и исключая способ, потому что, хотя оценки / концепции являются необходимым исданным ими, в связи с нынешней системой образования, они не могут представлять саму оценку, искажая процесс обучения. В этом типе оценки, которая классифицирует, 
наиболее здоровым является продукт. Отражая, образование, основанное на запоминании содержания.

В отличие от такого рода оценки, в которой особое внимание уделяется присвоению классов и классификации, можно доказать качественную оценку, основанную на критической парадигме и направленную на повышение качества системы образования. Учитывая, что его акцент делается на процессе преодоления трудностей студентов. И это оценка, которая в настоящее время желательно, перед лицом так много проблем, что школа проходит ежедневно.

В настоящее время существует консенсус в отношении новых методов оценки, которые внедряются в процессе обучения базовому образованию. Эта новинка в области педагогики породила участие студентов и способствовала с информацией и мнениями, которые могут способствовать преобразованию знаний и преподавания, и кульминацией с улучшением качества преподавания с введением, например, участия оценки целей, стратегии оценки, которые совпадают мнения и личное видение - критические или преодоления - стратегий, которые учителя приняли в классе.

Этот метод был использован для определения ощутимых результатов целей и педагогического планирования, рассматриваемых учителями, а также выявления точек, связанных с производительности фотографии (улучшение или ухудшение) студентов, а также выявление их мнения, если изменения будут приняты в нынешней педагогической практики. Согласно Kraemer (2005), эта практика имеет 2 важных функции, с своими краткими описаниями в диаграмме 1.

Таблица 1. Классификация функций оценки по целям.

\begin{tabular}{|l|l|}
\hline Классификации & Функции и характеристики \\
\hline $\begin{array}{l}\text { Диагностическая } \\
\text { функция }\end{array}$ & Среди его функций мы выделяем мнения тех, кто \\
оценивается в отношении управления стратегиями
\end{tabular}




\begin{tabular}{|c|c|}
\hline & $\begin{array}{l}\text { преподавания учителей, например; или даже взгляды } \\
\text { студентов на причины низкой производительности в } \\
\text { классе в данной дисциплине. Этот способ сбора } \\
\text { данных предлагает использование инновационных, } \\
\text { смелых и творческих предварительных тестов, } \\
\text { обследований и стратегий (мозг буря), которые } \\
\text { направлены на оказание помощи в диагностике } \\
\text { преподавания и принятие культуры изменений в } \\
\text { педагогических стратегий настоящее время. }\end{array}$ \\
\hline $\begin{array}{l}\text { Функция } \\
\text { суммирования, или } \\
\text { классифрикаторная }\end{array}$ & $\begin{array}{l}\text { Среди его основных характеристик, подчеркивается } \\
\text { принятие оценок, которые могут классифицировать и } \\
\text { охарактеризовывать понимание } \\
\text { разработанных учителями, или же, классификация } \\
\text { студента в конце учебного года (утверждены или } \\
\text { отклонены). Он был наиболее приемлемым в школах } \\
\text { для синтетического обеспечения построения } \\
\text { восприятия о школьной реальности в классе и в конце } \\
\text { бимастеров и семестров. }\end{array}$ \\
\hline
\end{tabular}

Fonte: Kraemer (2005).

При таком подходе можно сделать вывод о том, что оценка успеваемости в школе должна практиковаться в качестве атрибуции качества результатов обучения учащихся, основанной на его основных аспектах и что в качестве конечной цели, благоприятствует принятию решений, которые направляют обучение и, следовательно, развитие студента.

Таким образом, диагностическая оценка настроена как момент понимания стадии, на которой студент находится на расстоянии, на котором он ссылается на сфрормулированные цели, которые должны быть достигнуты заранее. Диагностическая оценка также благоприятствует социальному участию всех студентов как граждан, так как она больше не имеет консервативного и 
недемократического характера классификационной оценки, которая исключила многих людей из школы.

В этой предпосылке, диагностическая оценка направлена на выявление, проверку, изучение трудностей и целей, достигнутых в целях переопределения образовательного действия, и это процедурный акт, ведущий педагог задуматься о результатах своих исследований, создание новых предложений, методологий, с целью обучения качества и приверженности, необходимо постоянно оценивать студента , чтобы обнаружить различные моменты его развития, не ограничиваясь суждения об успехе или неудаче студентов, понимая его как набор спектаклей, который имеет функцию руководства педагогического вмешательства, это происходит постоянно и систематически через качественную интерпретацию знаний, построенных студентом.

Учитель будет использовать оценку в качестве инструмента, который позволяет ему постоянно подвергать сомнению свои предложения в процессе обучения, позволяя преподавателю перенаправить свою практику.

\section{5. ЗАКЛЮЧЕНИЕ}

Считается, что на проблему статьи был дан ответ, была достигнута общая цель и подтверждена гипотеза о том, что любой инструмент, используемый учителями и школой для проведения оценки, настраивает определенные, устанавливает уровень обучения, распознавает лучшее и худшее, и особенно, адаптировать преподавание к стандартам совершенства, установленным школой. Стандартизированные меры отвлекли демократическое, критическое, конструктивное и творческое чувство оценки, препятствуя эфрфективному обучению.

Цели также были достигнуты. Что касается цели анализа оценки преподавания и обучения, авторы проанализировали разоблачены происхождение методов оценки и их использования китайцами и греками на рынке труда. Знаком XIII века была организация оценочных экзаменов с присвоением оценок, что привело к RC: 50963

Disponível em: https://www.nucleodoconhecimento.com.br/образование-ru/оценка- 
науке под названием Docimologia. Сегодня были разработаны процедуры сравнения успеваемости учащихся с тестами и составом новых образовательных планов, включая оценку как процесс измерения этого показателя в дисциплинах.

Что касается второй конкретной цели, которая предложила проанализировать важность самооценки беспристрастного педагога, то в отобранных исследованиях было установлено, что схема самооценки состоит в том, чтобы внутренние и внешние процессы, в которых участвует школа, могли рационально измерять свои результаты и продемонстрировать эффективность того, как их педагогическое и дидактическое планирование дало удовлетворительные результаты в стратегиях преподавания в классах. таким образом, есть самооценка, когда можно определить сильные стороны (потенции) и хрупкие (эфемерис) в результатах.

Наконец, была достигнута третья конкретная цель, продемонстрировав, что использование оценки участия в целях бразильского базового образования приводит к тому, что они противоречат оценке, которая дает оценки и классифицирует. Основное внимание уделяется процессу преодоления трудностей студентов. И это оценка, которая в настоящее время желательно, перед лицом так много проблем, что школа проходит ежедневно. Этот метод был использован для определения ощутимых результатов целей и педагогического планирования, рассматриваемых учителями, а также выявления точек, связанных с производительности фротографии (улучшение или ухудшение) студентов.

\section{6. ССыЛкИ}

CAMILLONI, A. R. W. Los obstáculos epistemológicos em la enseñanza. Barcelona: Gedisa, 1997.

DEPRESBITERIS, Léa. O desafio da avaliação da aprendizagem: dos fundamentos a uma proposta inovadora. $1^{\text {a }}$ ed. São Paulo: Editora Pedagógica e Universitária, 1999.

Disponível em: https://www.nucleodoconhecimento.com.br/образование-ru/оценка- 
GARCIA, Ronaldo Coutinho. Subsídios para organizar avaliações da ação governamental. Planejamento e Políticas Públicas, Brasília, n. 23, p. 7-70, jan. /jun. 2001.

GIBBS, G. Uso estratégico de la evaluación en el aprendizaje. In: Brown, S.; Glasner, A. Evaluar em la Universidad: problemas y nuevos enfoques. Madrid: Narcea, 2003, pp. 61-70.

KRAEMER, Maria Elisabeth Pereira. A avaliação da aprendizagem como processo construtivo de um novo fazer. Avaliação: Revista da Avaliação da Educação Superior, v. 10, n. 2, 137-147, 2005.

SOEIRO, L \& AVELINE, S. Avaliação Educacional. Porto Alegre: Editora. Sulina, 1982. VIANNA, Heraldo Marelim. Fundamentos de um Programa de Avaliação Educacional. Brasília: Liber Livro Editora, 2005.

4. Testes normativos usados para avaliar a eficiência da Instituição escolar.

Опубликовано: Сентябрь, 2019.

Утверждено: ноябрь 2019 года. 